\title{
INCLUSIVE EDUCATION FROM A VERY BEGINNING: YEREVAN SCHOOL N20 \\ PRINCIPAL'S NARRATIVE
}

DOI: $10.24234 / \mathrm{se} .2021 .3 .1 .254$

\author{
AUTHORS' DATA \\ Anahit Khosrovyan, School Principal \\ John Kirakosyan Yerevan School N20, Armenia \\ Contacts: khosrovyan_a@mail.ru
}

\begin{abstract}
There are more than one billion "disabled persons" worldwide, $10 \%$ of whom are children mostly living in developing countries. Within the United Nations (UN) the term "disability" is defined as "any restriction or lack (resulting from an impairment) of ability to perform an activity in the way or within the range considered normal for a human being".

The UN and the United Nations Children's Fund (UNICEF) endeavour for all children to have equitable access to education as a basic human right. Education is critical for children to develop their human capital and enhance their upcoming economic and social prospects. The "Salamanca Statement" adopted at the "World Conference on Special Educational Needs: Access and Quality" called upon all governments and urged them to: adopt as a matter of law or policy the principles of inclusive education, enrolling all children in regular schools, unless

there are compelling reasons for doing otherwise.

In developing countries understanding of inclusive education is closely related to the special education needs of students and their participation in regular school classes. From this perspective, this paper aims to tell a story of one school in Yerevan, the capital of Armenia from the very beginning till nowadays.
\end{abstract}

Key words: inclusive education, education discrimination, special educational needs, people with disabilities, narrative.

\section{INTRODUCTION}

The Convention on the Rights of the Child (1990) combined with the Convention on the Rights of Persons with Disabilities (2006) forms the heart of the international framework protecting children from education discrimination. Still, from the earliest times of human development, the attitudes of 
people in society towards people with disabilities have changed. Thus, in the course of human development, the formation and definition of the rights of persons with disabilities have come a long way: from rejection to disappointment and then to the provision of numerous medical and social services (Harutyunyan \& Ghazaryan, 2017).

Inclusive education systems were expected to remove barriers limiting the participation and achievement of all learners; respect diverse needs, abilities, and characteristics; and eliminate all forms of discrimination in the learning environment (UNESCO, 2018). Children started to learn together and the practice of mere integration or partial participation in class fell into disuse. Ainscow, Booth, and Dyson (2006) defined inclusion as an approach to education representing specific values. According to the authors, inclusive education is concerned with all children and with overcoming barriers to all forms of marginalization, segregation, and underachievement. The authors claim that many popular studies still take a much narrower view of inclusion regarding children who have disabilities, or who are otherwise categorized as "having special educational needs" (Harutyunyan \& Sadlo, 2019; Sharma, 2015; Ainscow, Booth \& Dyson, 2006).

In Armenia, as in many countries of the world, there are a lot of data gaps regarding persons with disabilities, hindering the possibility to make informed policy choices in fulfilling their rights. Only the first steps toward including these persons into society, such as changing education policy and accepting inclusive education for children with special needs are done by different NGOs and governmental structures (Harutyunyan, Hovyan, Saratikyan, Azatyan, Muradyan \& Tanajyan, 2019). Inclusion is currently one of the most dispute and controversial topics involving current education practice. Success with the inclusion of children with special educational needs often depends on the perspectives of the teachers implementing the inclusion and multidisciplinary teams working with these children and their families. The process of inclusion can easily fail if the required supports and teacher commitment aren't presented (Harutyunyan, Hovyan, Saratikyan, Azatyan, Muradyan \& Tanajyan, 2019).

Many sources are reflecting on the issues and achievement in the field of inclusive education worldwide, but still, this evidence is mostly from United States of America or western European countries and does not necessarily apply to other countries, such as Armenia, due to cultural differences and inclusive school policies in these countries (Harutyunyan \& Harutyunyan, 2014).

While talking about Inclusive Education, the question becomes even more important because inclusion emphasizes the existence of persons with different abilities and diverse developmental problems in society. It is not a secret, that all these issues sometimes can be very lenient, which is related to the quality of the presentation of the idea of inclusion, the availability of physical and human resources for inclusive education, and other issues connected with the awareness and readiness of the society (Harutyunyan, Hovyan, Saratikyan, Azatyan, Muradyan \& Tanajyan, 2019). 
Inclusive education is more than the process of solving students' problems that fall outside the school system. Inclusive education itself gives equal opportunities to all learners, regardless of their disability, needs, age, sex, ethnicity, knowledge, or status (Moen \& Gudmundsdottir, 2003).

Based on all mentioned above, the current paper has an aim to describe the situation in Armenia, the path of inclusive education development from one school narrative example.

\section{METHODOLOGY}

Narrative research is the study of how human beings experience the world, and narrative researchers collect these stories and write narratives of experience (Gudmundsdottir, 2001). Narrative inquiry is a relatively new branch within the qualitative or interpretive research tradition. When reading about narratives and narrative research, one is left with the impression that the focus of attention becomes diffuse, spreading in many directions. Very often, the concept of narrative is used in connection with how to represent a qualitative research study (Moen, 2006).

The narrative approach is a frame of reference, a way of reflecting during the entire inquiry process, a research method, and a style for representing the research study. Hereafter, the narrative approach is both the phenomenon and the method (Connelly \& Clandinin, 1990), a hypothesis that some might find rather confusing and overpowering.

Still, within the frame of this paper, to understand the true situation, human beings, their actions, thoughts, and reflections, the environment, or the social, cultural, and institutional context in which the particular individual operates (Moen, 2006) were investigated and described.

In this paper, the perspective knowledge-for-practice is described. The focus here is on formal knowledge and theory, and the assumption appears to be that expert learners can be good teachers with more theoretical knowledge and experience (Cochran-Smith \& Lytle, 1999).

\section{A NARRATIVE}

For several years since 2007 till now John Kirakosyan Yerevan School No. 20 has been implementing inclusive education. During the first years of inclusive education, our school adopted the emotional approach explaining the values of inclusion to the school staff, parents, and students. And the following rules were implemented, met, and respected:

- Everyone has the right to express his opinion freely.

- Everyone has the right to belong to a society and to be a part of it. 
- Everyone has the right to get an education and to have a lifetime of learning.

- Everyone has the right to a company.

- Everyone gives his fruits to life because inclusion is not something mechanical but a general educational development process that includes access to education for all and meets all the needs of children.

A few years later we realized that we won`t succeed only based on emotions and it led us to create a work plan. We called it "From Emotions to Strong Professionalism" which was based on our mission to provide quality education by living together and creating a tolerant and equitable school life for all children. In other words, there should be an atmosphere in the school that would promote the slogan "Children must learn together".

It was necessary to take into account certain principles that were mandatory for the implementation of the given plan.

- Inclusive education should be supported not only by school staff, but also by parents, by the community, and all those whose intervention could be helpful in one way or another.

- Inclusive education eliminates discrimination, so all children, including children with special educational needs, should be encouraged to become full members of society, and all children should participate in all school events.

- The community and the public should be informed about the involvement by holding meetings and parent forums.

- The school must have a well-trained support team.

- Teachers need to be introduced to new teaching methods, especially student-centered ones, for the education of ALL children.

- The school building should be adapted to the needs of children with physical disabilities: ramps, handles.

- Wide introduction of Information and Communication technologies in the education process should be ensured.

And we managed to implement our plan, for which we are grateful to the Ministry of Education and Science of Republic of Armenia, Yerevan Municipality, UNICEF Children's Fund, "Bridge of Hope" and "Mission East" NGO-s, Pedagogical-Psychological Assessment Center for supporting and being next to our school. Because of this cooperation and strong mutual support:

- a strong multidisciplinary team was created: psychologists, special pedagogues, speech therapists, social workers, educators, art therapist; 
- an art therapy center was established which also became a centre for joint cooperation of children after classes;

- we managed to create opportunities for children to move freely and safely in the school building, even bringing down the classrooms to the first floor and buying a bus for transporting our students with special needs;

- trainings were organized for teachers not only on subjects or methodological topics but also on "Student social adjustment in school and in society":

- parents were involved in the school routine;

- the school-parent-community relationship was strengthened.

The support group was able to contact the facilitators in a short period, organize individual lessons after classes, develop a system of counseling for teachers in correcting individual tasks, problems, completing Individual Learning Plans.

The educational goals and goals that we set for ourselves at the beginning of the year increased during the year because the results shown by the children were more than we had expected. This is due to several factors but the primary role mainly is social cooperation.

Inclusion is a process of taking into account the diversity of the needs of all learners, taking into account the participation of all children, and reducing exclusion from the education system.

Inclusive education means the necessary individual support for people with disabilities to ensure their effective education and to maximize their educational and social development.

Yerevan school No.20 after John Kirakosyan where 90 students from 750 are with educational special needs, the idea of helping people is in the first place. Here children socialize with their peers, acquire skills to communicate with each other, express themselves, often participate in extracurricular activities, become self-confident.

They are happy, they smile and come to school with love and many of them are full members of society.

\section{LESSON TO LEARN}

The advice to my beginner colleagues in the frame of universal inclusion policy is:

"It is crucial that school staff adopts the three most important concepts in their work that should be placed above education. These are the three real indicators of quality education: participation, cooperation, equality. When there is an environment of full participation and cooperation for all learners and everyone has equal opportunities to develop, then we can say that education is of high 
quality. Teachers need to work more actively and systematically to achieve the goals of inclusive education." Khosrovyan, A., Yerevan, 2021.

\section{REFERENCE LIST}

1. Ainscow, M., Booth, T., \& Dyson, A. (2006). Improving schools, developing inclusion. New York, NY: Routledge.

2. Cochran-Smith, M., \& Lytle, S., L. (1999). Relationships of knowledge and practice: Teacher learning in communities. Review of Research in Education, 24, 249-306.

3. Connelly, M. F., \& Clandinin, J., D. (1990). Stories of experience and narrative inquiry. Educational Researcher, 19(5), p. 2-14.

4. Gudmundsdottir, S. (2001). Narrative research on school practice. In Richardson, V. (Ed.), Fourth handbook for research on teaching (pp. 226-240). New York: MacMillan.

5. Harutyunyan, M, Hovyan, G., Saratikyan, L., Azatyan, T., Muradyan, S., \& Tanajyan, K. (2019) Evaluation of universal inclusion processes consistency in Tavush, Lori and Syunik regions in the Republic of Armenia, Report, Khachatur Abovyan Armenian State Pedagogical University Research centre on inclusive community and disability issues, Caritas Armenia.

6. Harutyunyan, M., \& Sadlo, G. (2019). Inclusive Education in Armenia: Experience of Teachers Reveals Need for Occupational Therapy, The Journal of the International Association of Special Education 19(1), p. 27-36.

7. Harutyunyan, M., \& Ghazaryan, T. (2017). Hashmandamutyan ezruytin verabervogh kronakan, bzhshkakan ev socialakan tesaketnery, Krtutyuny ev gitutyuny Artsakhum, Hunvar-hulis 2017, 1-2, Gitamethodakan ev gitamatcheli parberakan sovoroghneri ev usucichneri hamar, ej 97-100, Asoghik.

8. Harutyunyan, Z., \& Harutyunyan, M. (2014). The system of inclusive education in Armenia and the role of occupational therapy in this system: Modern issues of psycho-pedagogical coexistence of children: Part I. Proceedings of the All-Russian Scientific and Practical Conference, Novosibirsk, Russia. Murph, R., F. (2001). The Body Silent: The Different World of the Disabled.

9. Moen, T. (2006). Reflections on the Narrative Research Approach, International Journal of Qualitative Methods, Vol.: 5 (4), p. 56-69.

10. Moen, T., Gudmundsdottir, S., \& Flem, A. (2003). Inclusive practice: A biographical approach. Teaching and Teacher Education, 19, 359-370. 
11. Sharma, A. (2015). Perspectives on Inclusive Education with Reference to United Nations, Universal Journal of Educational Research 3(5): 317-321, DOI: 10.13189/ujer.2015.030502.

12. UNESCO. (2018). Inclusion in education. Retrieved from https://en.unesco.org/themes/inclusion-in-education.

13. UNESCO. (1994). The Salamanca statement and framework for action on special needs education. Paris: UNESCO.

14. UN. (1990). Convention on the Rights of the Child.

15. UN. (2006). Convention on the rights of persons with disabilities. 